\title{
CORRELAÇÕES CANÔNICAS : II - ANÁLISE DO RENDIMENTO DE GRÃOS DE FEIJÃO E SEUS COMPONENTES
}

\author{
CANONICAL CORRELATIONS: II - ANALISYS OF \\ BEAN YIELD AND YIELD COMPONENTS
}

\author{
Jefferson Luís Meirelles Coimbra ${ }^{1}$ Altamir Frederico Guidolin ${ }^{2}$ Fernando Irajá Felix de Carvalho ${ }^{3}$ \\ Roni de Azevedo ${ }^{4}$
}

\section{RESUMO}

Trinta e dois genótipos de feijão (Phaseolus vulgaris L.) foram avaliados em Lages/SC, em sete caracteres de importância agronômica e da produção de grãos por unidade de área. $O$ experimento, em blocos casualizados com quatro repetições, foi conduzido no período de "safrinha", no ano agrícola de 1995/96. Este trabalho teve como objetivo estimar a intensidade de associação entre os grupos primários e secundários responsáveis pelo rendimento de grãos. O primeiro grupo de variáveis (primários) foi constituído pelo número de grãos por legume, número de legumes por planta e a massa de mil grãos; e o segundo grupo (secundários), pelo número de dias entre a emergência e o florescimento, número de dias entre a emergência e a maturação de colheita, estatura de planta e estatura de inserção do primeiro legume. Pela análise das correlações canônicas, ficou evidenciada a importância dos caracteres agronômicos secundários sobre o número de legumes por planta e sobre o número de grãos por legume; sendo assim, os coeficientes de correlações canônicas permitem concluir que, em programas de melhoramento genético de feijão, para incrementar o rendimento de grãos devem ser selecionadas plantas com maior número de legumes por planta, que tendem a proporcionar plantas com maior estatura e de ciclo longo.

Palavras-chave: Phaseolus vulgaris L., critérios de seleção, melhoramento vegetal.

\section{SUMMARY}

Thirty two bean genotypes (Phaseolus vulgaris L.) were evaluated in Lages/SC, Brazil, on the influence of seven characters of agronomic importance on the production of grains per unit of area. The experiment, in randomized blocks with four repetitions, was driven in the off season period in the agricultural year of 1995/96. This work aimed to estimate the intensity the association between the primary and secondary components of grain yield. The first group of variables (primary) was constituted by the number of grains per pod, number of pods per plant and the weight of a thousand grains. The second group (secondary) consisted of number of days from emergency to flowering, number of days from emergency to harvesting point, plant stature and the first pod insertion point. For the analysis of canonical correlations, the importance of secondary agronomic characters was evident in the traits number of pods per plant and grains per pod and also the influence of both on the final grain yield. Therefore, the coefficients of canonical correlations indicate that, in programs bean genetic improvement programs, to increase the production of grains one should select plants with larger number of pods per plant in order to obtain plants with higher stature and longer cycle.

Key words: Phaseolus vulgaris L., selection criterian, crop breeding.

\section{INTRODUÇÃO}

O feijão (Phaseolus vulgaris L.) é uma das leguminosas mais importantes do Sul do Brasil, tanto em área cultivada quanto em volume de produção de grãos (JOBIM, 1990). De acordo com este autor, o feijão, no Brasil, ainda é cultivado em pequenas propriedades e com baixos rendimentos de grãos.

O baixo rendimento de grãos por unidade de área evidenciado para esta cultura no Brasil (470kg/ha), segundo MIRANDA et al. (1988), é

\footnotetext{
${ }^{1}$ Engenheiro Agrônomo, aluno do Curso de Pós-graduação em Agronomia, Universidade Federal de Pelotas (UFPel). Bolsista da CAPES. CP 354, 96001-970, Capão do Leão, RS. jlmcpos@ufpel.tche.br.

${ }^{2}$ Engenheiro Agrônomo, MSc., Professor de Genética, Centro de Ciências Agroveterinárias, Universidade do Estado de Santa Catarina.

${ }^{3}$ Engenheiro Agrônomo, PhD., Prof. da Faculdade de Agronomia, UFPel. Pesquisador do CNPq.

${ }^{4}$ Aluno do curso de Agronomia/Bolsista de Iniciação Científica do CNPq. 
decorrente, em parte, da falta de cultivares mais produtivos, com acentuada estabilidade e adequada capacidade de adaptabilidade. Considerando as inúmeras variações de ambiente a que o feijoeiro é comumente submetido no Brasil, RAMALHO et al. (1979) comentam que é esperado que a interação de genótipos por ambientes assuma papel fundamental na manifestação fenotípica. Portanto, é importante o conhecimento dos fatores genéticos responsáveis pelo incremento no potencial de rendimento de grãos, bem como identificar e avaliar a variabilidade genética existente no "Pool Gene". Tal fato indica viabilidade na obtenção de progresso genético com a seleção de genótipos superiores, desde que exista acentuada variabilidade genética no germoplasma.

Para SANTOS \& VENCOVSKY (1986), a correlação entre os componentes do rendimento de grãos é importante, em particular, para o melhoramento genético de plantas e, principalmente, quando ao se efetuar a seleção com base em um caráter, resultam alterações em outros caracteres de importância agronômica correlacionados entre si. A seleção de genótipos superiores tem o objetivo de identificar simultaneamente vários caracteres e o conhecimento das correlações fenotípicas poderá auxiliar a seleção de um ideótipo de planta mais adequada às exigências de uma agricultura moderna e competitiva. Para CRUZ (1997), a correlação simples permite avaliar a magnitude e a direção das relações entre dois caracteres, sendo de grande utilidade no melhoramento genético por permitir avaliar a viabilidade do emprego da seleção indireta que, em alguns casos, pode levar a progressos genéticos mais rápidos e altamente expressivos em programas de melhoramento genético de feijão. Porém, esta técnica não permite avaliar as inter-relações entre dois grupos de variáveis determinados por um número maior de caracteres de importância agronômica. A maioria das correlações, para os autores VENCOVSKY \& BARRIGA (1992), são explicadas pelos efeitos aditivos dos genes, afetando simultaneamente dois caracteres agronômicos.

A técnica de correlação canônica pode ser mais apropriada para estimar as relações entre dois grupos de caracteres agronômicos. Essa técnica pode ser utilizada para avaliar as relações de parte aérea e sistema radicular, caracteres primários e secundários da produção e/ou caracteres fisiológicos e agronômicos (SANTOS et al., 1994). Além disso, os pesquisadores CRUZ \& REGAZZI (1997) comentam que a grande vantagem dessa técnica é a possibilidade em auxiliar o melhorista no estudo que envolva mais de uma variável dependente, permitindo que os esforços sejam dirigidos para caracteres de alta herdabilidade, de fácil mensuração e de menos comple- xidade na produção de grãos no melhoramento genético de plantas.

Este trabalho teve por objetivo estimar as correlações canônicas e as inter-relações entre os componentes primários e secundários do rendimento de grãos no feijão.

\section{MATERIAL E MÉTODO}

Trinta e dois genótipos de feijão preto foram caracterizados no ano agrícola de 1995/96, no município de Lages/SC, situado no Planalto Catarinense. Oito caracteres foram utilizados para determinação das correlações fenotípicas e, posteriormente, para a análise das correlações canônicas realizadas sobre sete variáveis. As variáveis explicativas primárias foram número de grãos por legume (NGL), número de legumes por planta (NLP) e massa de mil grãos (MMG) e, os quatro caracteres secundárias foram o número de dias para floração (FL) e colheita (MC), estatura de planta (EP) e estatura de inserção do primeiro legume (EIL). As avaliações realizadas foram baseadas nos estádios de crescimento da cultura, seguindo a escala proposta pelo CIAT (1991). A emergência foi avaliada no estádio $\mathrm{V}_{1}$, a data de floração no estádio $\mathrm{R}_{6}$ e o período de maturação de colheita no estádio $\mathrm{R}_{9}$ (quando $50 \%$ dos legumes da parcela experimental estavam aparentemente em maturação fisiológica). A determinação do ponto de inserção do primeiro legume foi avaliada no estádio $R_{7}$ (quando surgiu o primeiro legume que media mais de $2,5 \mathrm{~cm}$ de comprimento).

O preparo do solo foi realizado segundo recomendações técnicas relatadas por WILDNER (1992). As adubações seguiram as recomendações descritas pelos autores BALDISSERA \& SCHERER (1992). O controle de plantas invasoras foi efetuado com aplicação de $2 \mathrm{~kg} /$ ha de Metolachlor, posteriormente, realizou-se capina manual para eliminação das invasoras remanescentes. Para o controle de pragas, foi utilizado o inseticida Methamidophos (Tamaron BR) nas doses de 1,01/ha do produto comercial. $\mathrm{O}$ delineamento experimental utilizado foi blocos ao acaso, com quatro repetições. Cada unidade experimental foi composta por duas fileiras de $5 \mathrm{~m}$ de comprimento com 10 plantas/m linear ou 200.000 plantas/ha, com espaçamento de $0,5 \mathrm{~m}$ entre fileiras e $0,2 \mathrm{~m}$ entre covas dentro das fileiras. A área útil foi formada de duas fileiras, compreendendo $4 \mathrm{~m}^{2}$. A semeadura foi realizada em 09 de fevereiro de 1996. A época de semeadura, de acordo com HEMP et al. (1993), não coincide com o período preferencial para a cultura naquela região.

As correlações canônicas foram estimadas entre o grupo de variáveis constituído pelos caracte- 
res agronômicos primários (NGL, NLP e MMG) e o grupo de variáveis constituído pelos caracteres agronômicos secundários (FL, MC, EP e EIL) do feijão, de acordo com os procedimentos descritos por CRUZ \& REGAZZI (1997).

A hipótese de nulidade:

$\left(\mathrm{H}_{0}: \rho_{1}=\rho_{2}=\ldots \ldots=\rho_{\mathrm{n}}=0, \mathrm{~s}=\min \{\mathrm{p}, \mathrm{q}\}\right)$

para as correlações canônicas foram testadas por meio do teste do qui-quadrado. A hipótese de que o coeficiente de correlação fenotípico é igual a zero $\left(\mathrm{H}_{0}: 0\right)$ foi avaliada pela estatística $\mathrm{t}$, segundo metodologia proposta por STEEL e TORRIE (1960). As análises foram realizadas, usando o programa computacional GENES (CRUZ, 1997) e SAS.

\section{RESULTADOS E DISCUSSÃO}

As estimativas dos coeficientes de correlação fenotípica avaliadas para os sete caracteres de importância agronômica são apresentados na tabela 1. Com relação à magnitude das correlações entre todos os caracteres avaliados, variaram de 0,003 a 0,89. Porém, CRUZ \& REGAZZI (1997) apontam que o coeficiente de correlação igual a zero não implica falta de correlação entre duas variáveis, apenas reflete a ausência de relação linear entre estes caracteres avaliados. A correlação fenotípica mede o grau de associação de dois caracteres provenientes do efeito do ambiente e genético, sendo este último efeito o principal responsável pela fração herdável dos genitores para as progênies. Ainda observando a tabela 1 , pode ser notado que houve uma discordância no sentido das correlações estimadas, revelando

Tabela 1 - Coeficientes de correlações fenotípicas entre os 32 genótipos, para oito caracteres de importância agronômica, número de dias entre a emergência e o florescimento (FL), número de dias entre o florescimento e a maturação de colheita (MC), estatura de planta (EP), estatura de inserção do primeiro legume (EIL), número de grãos por legume (NGL), número de legumes por planta (NLP), massa de mil grãos (MMG) e o rendimento de grãos (PROG) obtidos no Ensaio Sulbrasileiro de feijão preto no município de Lages/SC, no ano agrícola de 1995/96.

\begin{tabular}{lcccccccc}
\hline Caracteres & FL & MC & EP & EIL & NGL & NLP & MMG & PROG \\
& & & & & & & & \\
\hline FL & \multirow{2}{*}{1,00} & $0,41^{*}$ & 0,19 & $0,29^{*}$ & $-0,21^{*}$ & 0,11 & $-0,22^{*}$ & $-0,13$ \\
MC & & 1,00 & $0,27^{*}$ & 0,01 & $-0,26^{*}$ & $0,24^{*}$ & $-0,02$ & $-0,25^{*}$ \\
EP & & & 1,00 & 0,17 & $-0,36^{*}$ & $0,23^{*}$ & 0.13 & $-0,06$ \\
EIL & & & & 1,00 & $-0,30^{*}$ & $-0,32^{*}$ & $-0,003$ & $-0,18$ \\
NGL & & & & & 1,00 & 0,09 & $-0,10$ & $0,37^{*}$ \\
NLP & & & & & & 1,00 & $-0,29^{*}$ & $0,89^{*}$ \\
MMG & & & & & & & 1,00 & $0,46^{*}$ \\
PROG & & & & & & & & 1,00 \\
& & & & & & &
\end{tabular}

${ }^{*}$ significativo pelo teste de t a 0,05 de probabilidade, com 93 graus de liberdade do erro. que as causas de variação influenciaram os caracteres por meio de diferentes mecanismos fisiológicos (FALCONER \& MACKAY, 1996). GEADELMANN e FREY (1975) comentam que a seleção para qualquer caráter secundário não tem valor se o desempenho deste caráter não é correlacionado com o desempenho do caráter primário. Fato este, que pode ser observado na tabela 1 , onde o coeficiente de correlação entre os caracteres número de dias entre a emergência e o florescimento, número de dias entre a emergência e a maturação de colheita, estatura de planta e estatura de inserção do primeiro legume com o rendimento de grãos, evidenciou uma lação fenotípica negativa. Os caracteres número ciaram um grau de associação elevado com o caráter rendimento de grãos por unidade de área. Estimaticomo ciclo da cultura e estatura de planta têm sido (reqüentemente estudados (SANTOS et al., 1986; RAMALHO et al., 1978; RAMALHO et al., 1979; DUDLEY \& MOLL 1969; FEHR, 1987).

Todas as três correlações canônicas (tabela 2) foram significativas em nível de $1 \%$ de probabilidade $(\mathrm{p}<0,01)$, pelo teste do qui-quadrado; conseqüentemente, os três pares canônicos são de interesse do estudo. Pelos coeficientes do primeiro par canônico ficou evidenciado a relação entre plantas com baixa estatura de inserção do primeiro legume, maior estatura de planta e número de dias entre a emergência e o florescimento, caracteres do grupo II; são determinantes no decréscimo do número de grãos por legume e pelo incremento da massa de mil grãos, caracteres do grupo I, ou seja, para a obtenção de uma planta com maior número de grãos por legume é necessário selecionar planta de menor estatura de planta, maior número de dias entre a emergência e a maturação de colheita e com menor estatura de inserção do primeiro legume. Por outro lado, plantas com maior número de legumes, que é o caráter mais correlacionado com a produtividade de grãos, são proporcionadas por plantas com maior estatura de planta, com menor estatura de inserção do primeiro legume e maior ciclo reprodutivo.

Ainda na tabela 2 , pode ser observado, no segundo par de correlação canônica, que plantas com 
Tabela 2 - Correlações canônicas e pares canônicos $\left(a_{i}\right.$ e $\left.b_{i}\right)$ estimados entre componentes primários Grupo I: número de grãos por legume (NGL), número de legumes por planta (NLP) e massa de mil grãos (MMG) e secundários Grupo II: número de dias entre a emergência e o florescimento (FL), número de dias entre o florescimento e a maturação de colheita (MC), estatura de planta (EP) e estatura de inserção do primeiro legume (EIL) da produtividade de grãos da cultura de feijão, no município de Lages/SC, safra de 1995/96.

\begin{tabular}{|c|c|c|c|c|c|c|}
\hline \multirow[t]{2}{*}{ Caracteres } & \multicolumn{6}{|c|}{ Pares canônicos } \\
\hline & \multicolumn{2}{|c|}{$1^{\circ}$} & \multicolumn{2}{|c|}{$2^{\circ}$} & \multicolumn{2}{|r|}{$3^{\circ}$} \\
\hline & \multicolumn{6}{|c|}{------ Grupo I ------ } \\
\hline NGL & $a_{11}$ & $-0,5246$ & $a_{21}$ & 0,8535 & $a_{31}$ & 0,1090 \\
\hline NLP & $a_{12}$ & 0,9154 & $a_{22}$ & 0,4952 & $a_{32}$ & $-0,1235$ \\
\hline MMG & $a_{13}$ & 0,3646 & $a_{23}$ & 0,2004 & $a_{33}$ & 0,9631 \\
\hline & \multicolumn{6}{|c|}{------ Grupo II ------ } \\
\hline FL & $b_{11}$ & 0,0221 & $\mathrm{~b}_{21}$ & $-0,0195$ & $\mathrm{~b}_{31}$ & $-0,2854$ \\
\hline MC & $b_{12}$ & 0,2538 & $\mathrm{~b}_{22}$ & $-0,0316$ & $\mathrm{~b}_{32}$ & 0,0094 \\
\hline EP & $b_{13}$ & 0,4057 & $b_{23}$ & $-0,0918$ & $\mathrm{~b}_{33}$ & 0,1001 \\
\hline EIL & $\mathrm{b}_{14}$ & $-0,2341$ & $b_{23}$ & $-0,3939$ & $\mathrm{~b}_{34}$ & 0,0690 \\
\hline $\mathrm{r}$ & & 0,5491 & & 0,4314 & & 0,2740 \\
\hline significância (p) & \multicolumn{2}{|c|}{$<0,01$} & \multicolumn{2}{|c|}{$<0,001$} & \multicolumn{2}{|r|}{$<0,01$} \\
\hline G.L & \multicolumn{2}{|c|}{16} & \multicolumn{2}{|c|}{6} & \multicolumn{2}{|r|}{2} \\
\hline
\end{tabular}

mais precoces e plantas com maior estatura e maior estatura de inserção do primeiro legume, principalmente. Este caráter apontou a maior correlação com o caráter produtividade de grãos por unidade de área. Conforme descrito por SANTOS et al. (1994), a análise da correlação canônica revelou uma associação positiva entre os caracteres ciclo vegetativo e estatura de planta com a produtividade de grãos, ou seja, quanto maior a estatura de planta, provavelmente maior será a produtividade de grãos por unidade de área.

\section{CONCLUSÕES}

Os componentes primários e secundários do rendimento de grãos de feijão preto não são independentes. As associações intergrupos são estabelecidas, principalmente, pelas influências de: plantas com maior estatura e maior ciclo reprodutivo influenciam negativamente o número de grãos por legume e, positivamente, o número de legumes por planta e a massa de grãos; quanto menor o número de

menor número de dias entre a emergência e a maturação de colheita, menor estatura de planta e menor estatura de inserção do primeiro legume, tendem a proporcionar plantas com maior número de grãos por planta. O segundo par canônico revelou também que existe uma dependência significativa entre os dois grupos de caracteres primários e secundários e que suas relações são explicadas por plantas precoces e de menor estatura de inserção do primeiro legume com plantas de maior número de legumes por planta. A correlação canônica também foi estimada por MIRANDA et al. (1988), entre caracteres agronômicos e físico-químicos na batata doce SANTOS et al. (1994). Estes autores estimaram a associação entre caracteres primários e caracteres secundários da produção de grãos em guandu e, COIMBRA et al. (1998 a) e COIMBRA et al. (1998 b), onde foi estimado a relação entre caracteres primários do rendimento de grãos e fitossanitários com o rendimento de grãos em feijão.

Os resultados evidenciados pelo terceiro par canônico (tabela 2) apontaram que plantas com maior massa de mil grãos são influenciadas por plantas dias entre a emergência e o florescimento, ciclo reprodutivo e estatura de planta maior se número de legumes por planta enquanto que menor número de dias entre a emergência e o florescimento, maior estatura de planta, proporcionam maior massa grãos.

\section{REFERÊNCIAS BIBLIOGRÁFICAS}

ABREU, A.F.B., RAMALHO, M.A.P., SOUZA, E.A., $\boldsymbol{e t}$ al. Seleção de cultivares de feijão (Phaseolus vulgaris L.) precoce com grão do tipo carioca e resistente a antracnose. Ciência e Prática, Lavras, v. 14, n. 1. p. 72-82, 1990.

AMARAL, A.L., CARVALHO, F.I.F., FEDERIZZI, L.C., $\boldsymbol{e} \boldsymbol{t}$ al. Estimativa da herdabilidade para os caracteres adaptativos ciclo e estatura de planta em aveia. Ciência Rural, Santa Maria, v. 26, n.1. p. 33-37, 1996.

BALDISSERA, I.T., SCHERER, E.E. Correção da acidez do solo e adubação da cultura do feijão. In: EPAGRI. A cultura do feijão em Santa Catarina. Florianópolis: EPAGRI, 1992. Cap. 6. p.115-136.

CIAT - CENTRO INTERNACIONAL DE AGRICULTURA TROPICAL. Sistema Estándar para la evaluación de Germoplasma de Frijol. 2. ed. Cali, Colômbia: CIAT, 1991. $56 \mathrm{p}$. 
COIMBRA, J.L.M., COIMBRA, S.M.M., CARVALHO, F.I.F., et al. Coeficientes de trilha, correlações canônicas e divergência genética: II. Entre caracteres primários e fitossanitários em genótipos de feijão preto (Phaseolus vulgaris L.). Pesquisa Agropecuária Gaúcha, Porto Alegre, v. 04, n. 02, 1998 b (no prelo).

COIMBRA, J.L.M., GUIDOLIN, A.F., CARVALHO, F.I.F. Coeficientes de trilha, correlações canônicas e divergência genética: I. Entre caracteres primários e secundários do rendimento de grãos em genótipos de feijão preto (Phaseolus vulgaris L.). Pesquisa Agropecuária Gaúcha, Porto Alegre, v. 04, n. 02, 1998 a (no prelo).

CRUZ, C.D. Aplicativo computacional em genética e estatística. Viçosa: UFV, 1997. 442 p.

CRUZ, C.D., REGAZZI, A.J. Modelos Biométricos Aplicados ao Melhoramento Genético. 2. ed. Viçosa: UFV, 1997. 390 p.

DUDLEY, J.W., MOLL, R.H. Interpretation and use of estimates of heritability and genetic variances in plant breeding. Crop Science, Madison, v. 9, n. 3, 257-261.1969.

FALCONER, D.S., MACKAY, T.F.C. Introduction to quantitative genetics. 4 ed. England: Longman, 1996. 463 p.

FEHR, W.R. Principles of cultivars development. New York: Macmillan Publishing, 1987. v. I. 536 p

GEADELMANN, J.L., FREY, K.J. Direct and indirect selection mass selection for grain yield in bulk oat populations. Crop Science, Madison, v. 15, 490-494, 1975.

HEMP, S., MASSIGNAM, A.M., GANDIM, C.L., et al. Feijão In: EPAGRI. Recomendações de cultivares para o Estado de Santa Catarina 1993/1994. Florianópolis: EPAGRI, 1994. p. 55-61. 1994. Boletim técnico n. 67.

JOBIM, C.I.P. Utilização de variáveis ambientais na análise da interação genótipoxambiente em feijão (Phaseolus vulgaris
L.). Porto Alegre: UFRGS, 1990. 84 p. Dissertação (Mestrado em Fitotecnia) - Programa de Pós - graduação em Agronomia, Universidade Federal do Rio Grande do Sul. 1990.

MIRANDA, J.E.C., CRUZ, C.D., PEREIRA, A.S. Análise de trilha e divergência genética de cultivares e clones de Batatadoce. Revista Brasileira de Genética. Ribeirão Preto, v. 11, n. 4. p.881-904, 1988.

RAMALHO, M.A.P., SANTOS, J.B., SANTA CECÍlIA, F.C. et $\boldsymbol{a l}$. Seleção de progênies no feijão "Pintado" e estimativa dos parâmetros genéticos e fenótipicos. Ciência e Prática, Lavras, v. 3, p. 51-57, 1979.

RAMALHO, M.A.P., VENCOVSKY, R. Estimação dos componentes da variância genética em plantas autógamas. Ciência e Prática, Lavras, v. 10, n. 2. p. 117-140, 1978.

SANTOS, C.A.F., CAVALCANTI, J., PAINI, J.N. $\boldsymbol{e} \boldsymbol{t} \boldsymbol{a l}$. Correlações canônicas entre componentes primários e secundários na produção de grãos em Guandu (Cajanus cajan (L.) Millsp). Revista Ceres, Viçosa, v. 41, n. 236. p. 456-464, 1994.

SANTOS, J., VENCOVSKY, R. Correlação fenotípica e genética entre alguns caracteres agronômicos do feijoeiro (Phaseolus vulgaris L.). Ciência e Prática, Lavras, v. 10, n. 3. p. 265$272,1986$.

SAS User's Guide: Statistics, Version 5 Edition. Cary, NC: SAS Institute Inc., 1985. 965 pp.

STEEL, R.G.D., TORRIE, J.H. Principles and procedures of statistics. 2. ed. New York: McGraw-Hill, 1960. 473 p.

VENCOVSKY, R., BARRIGA, P. Genética biométrica no fitomelhoramento. Ribeirão Preto: Revista Brasileira de Genética, 1992. 496 p.

WILDNER, L.P. Manejo do solo para cultura do feijão: Principais características e recomendações técnicas. In: EPAGRI. A cultura do feijão em Santa Catarina. Florianópolis: EPAGRI, 1992. Cap. 5. p.83-114.

Ciência Rural, v. 30, n. 1, 2000. 